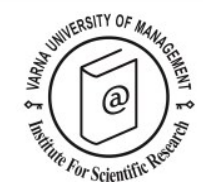

\title{
Staiff, R. (2014) Re-imagining heritage interpretation - enchanting the Past-Future Farnham: Ashgate Publishing ISBN 9781409455509 (hbk), 194 pages
}

\author{
Reviewed by Professor Alan Clarke
}

Received: 14/08/2014

\footnotetext{
${ }^{1}$ University of Pannonia, Veszprém, Hungary, E-mail: clarke@turizmus.uni-pannon.hu
}

(C) 2015 Varna University of Management. All rights reserved

Citation Staiff, R. (2014) Re-imagining heritage interpretation - enchanting the Past-Future Farnham: Ashgate Publishing. 194 pp. ISBN 9781409455509 (hbk), Reviewed by Professor Alan Clarke, European Journal of Tourism Research 10, pp. 140-141

It is refreshing to find a single authored book in these days of edited collections. Here Staiff has the opportunity to develop his thoughts at full length and takes his readers on a journey through the past, present and future of his own experiences of Heritage around the world. The Prologue makes it clear what this book is not intended to be - it is not a heritage interpretation manual as it is "a series of personal meditations about the relationships between heritage places and visitors; it is a cultural study of the phenomenon now known globally as heritage interpretation. And it is an intensely individualistic account." (Original emphasis, p.3) His conversations include the personal, sensory and emotional elements, calling for a dialogic engagement with heritage sites arguing that this inclusivity could create far more meaningful, intense and memorable experiences of places.

The author moves through a number of key issues in heritage interpretation, questioning Tilden, exploring embodied heritage experiences, examining visual cultures, narrativity, the digital media and social 140 networks, cross cultural concerns and ending with a concluding chapter that focuses on imaginings outside didacticism. It is a massive agenda and one which the author does well to address as it creates the basis for him to posit reconsideration and perhaps even a relocation of the focus for heritage interpretation. Staiff has attempted more than a simple account of interpretation could ever do.

Staiff also claims that this is not a traditional academic analysis because it eschews the normal forms of address in favour of retelling narratives, describing encounters and reworking conversations in way that opens the possibility of dialogues with students, practitioners and colleagues. It will have value to many who enter into these accounts and it will provoke many responses ranging from the positive to the negative but it will provoke!

In this spirit, this review seeks to take up some of these conversations with the author and will begin by addressing one of the central tenets of the argument put forward. $\mathrm{He}$ argues that heritage has become focussed on 
the educational elements of heritage sites and has valued, possibly over valued the learning that is made possible at these sites. This is an interesting thesis and is supported by suggestions that in the digital age it is no longer necessary to present a single explanatory narrative to the visitors, who will be more or less capable of coming up with their materials from the Internet to inform their own expectations and their own experiences.

Here in lies the basis of the challenge to the official interpretation, Staiff sees this as but one of many possible narratives that could be created by either the curators or the visitors to the sites. This much is true but by looking beyond the heritage settings to the literature on the experience economy and the rapidly growing amount of work on co-creation, the re-imagining could need to be much more radical than it turns out to be. Whilst it is certain that there are more sources of information on the web, it is not clear that those sources support or are supported by alternative epistemologies of the sites, experiences and objects that they address. Staiff points out that our understanding of narrativity is easiest when it deals with stories of cause and effect. We construct our stories in the context of narrative conventions that we are familiar with. These tend to be set in our own universe and we create meaning(s) within those contexts.

If we unpack this notion of meaning making a little further, it becomes necessary to also question the disciplinary power of the universe. For co-creation, with the bringing together of experience from both the heritage suppliers and the heritage visitors we have to do more than recognise the possibility of different interpretations, we have to recognise the possibility of different ways of seeing the world(s) altogether as we recognise the value in our multiverse of diverse narratives. Just as Staiff recognises the rules of composition in different cultures' constructions of 'art' with different horizons set as the 'norm' so we have to accept that there are valid narrative structures, which are capable of 'imagining' our experiences in different perspectives. He begins to address this when discussing the incommensurability of Western interpretations of Uluru-Kata Tjuta but there is a conversation to be had about what it is that prevents Western understandings of the ways of thinking embodied in the site. One example is the use of the word 'law' to describe the concept at the heart of the indigenous understanding of the sites significance. In this case our $21^{\text {st }}$ Century westernised understanding sets us apart. 'Law' is about law and order, government acts that permit or prohibit certain behaviour, enforced by an external police and often recognised in the breach (all you motorists know the 'law' and never drive above the speed limit or talk on your mobile phones whilst driving). This is not what is being talked about here, our understanding comes closer to 'law' where we move to think in different terms, perhaps 'thinking' 'lore' or even 'identity'. Re-imagining calls into question our knowledges about the way the worlds work and the relationships between the elements in them - indeed a polysemic multiverse.

This book can be read as a challenge to monoversal accounts coming from the interpretation industry. It contains many rich and vivid stories, portraying some of the complex relationships we have with our heritages. However there are more conversations to be held about the nature of power in the definitional processes embedded in heritage interpretations and the way that heritages work and are worked to support, oppress and repress groups within the multiverse. We also have to consider that some heritages are dark and that the interpretations will be uncomfortable no matter how we access them in our digital worlds. Read the book and take up the conversations, you do not have to agree with all of the interpretations offered here but they are worth considering, challenging and taking on to the next level of informing our narratives of our heritages. 